\title{
Air Suspension System
}

\section{Lalank Samudra Mukti Hidayat}

Mahasiswa Program Studi Mesin Otomotif,

Fakultas Teknik, Universitas Muhammadiyah Magelang

Email: lalanksamudra349@gmail.com

\section{Ringkasan}

Fungsi utama dari suspensi yaitu sebagai peredam kejut atau sock breaker dan penopang hentakan yang terjadi, sehingga ketika berkendara penumpang tetap merasa nyaman. Penggunaan suspensi udara sebagai pengganti suspensi baja jelas sebagai suatu perkembangan dari teknologi. Suspensi udara memiliki keunggulan lebih dari suspensi baja, diantaranya dengan suspensi udara goncangan atau getaran yang terjadi ketika di jalan akan terasa lebih halus.

\section{Pendahuluan}

Saat ini, keselamatan berkendara menjadi issue utama dalam pengembangan mobil. Mulai dari system kontrol mekanikal sampai dengan kontrol elektronik [1]. Salah satu komponen utama pendukung keselamatan berkendara adalah system suspensi. Sistem suspensi mobil berfungsi untuk menjaga mobil tetap terkendali dan membuat nyaman kendaraan. Secara khusus, sistem suspensi memaksimalkan gesekan antara ban dengan jalan untuk memberikan stabilitas kemudi dan handling yang baik. Sistem suspensi juga berfungsi untuk meminimalisir dampak dari kondisi jalan tertentu tidak hanya kendaraan, tetapi juga penumpang yang berada di dalam [2].

Sistem suspensi terdiri dari beberapa komponen, termasuk sasis yang memegang kabin mobil. Pegas menompang bobot kendaraan dan menyerap serta mengurangi guncangan berlebih dari jalan. Bar stabilizer menggeser gerakan roda dan mensabilkan mobil dari guncangan.

Sistem suspensi harus berada pada kondisi prima. Komponen suspensi yang aus dapat mengurangi stabilitas kendaraan dan mengurangi kontrol pengemudi, serta dapat mempercepat keausan pada komponen sistem suspensi yang lainnya. Mengganti komponen yang sudah aus atau tidak memadai akan membantu handling yang lebih baik, karena:

- kontrol pegas dan gerakan suspensi

- memberikan pengendalian lebih baik pada saat pengeraman 
- cegah keausan ban dan menjaga agar roda tetap menapak pada jalan

- mempertahankan agar roda tetap lurus

- mengurangi keausan pada sistem yang lain

- menjaga keausan ban dan rem agar tetap rata

William Humphreys pada tahun 1901 memberi solusi efektif dengan menciptakan sistem suspensi udara yang idenya ia dipatenkan. Prinsip sistem suspensi ini adalah menggantikan per baja dengan bantalan udara, yang dapat diatur tingkat kekerasannya secara fleksibel sambil berjalan.

Fleksibilitas membuat dua karakter suspensi yang sebelumnya saling bertolak belakang bisa akur dalam satu rumah. Kehebatan suspensi udara ini mampu membuat Range Rover sejak generasi kedua bisa tetap mempertahankan kemampuan off-road-nya. Travel suspensi panjang dan lentur sekaligus dapat mencengkeram aspal dengan kuat layaknya sedan-sedan premium saat dipacu pada kecepatan tinggi. Suspensi udara juga memungkinkan mobil punya kemampuan auto levelling. Di mana bodi relatif tetap rata, saat roda roda mengikuti kontur jalan. Bodi kendaraan juga tidak mendongak saat bagian belakang mengangkut muatan ekstra. Secara sederhana, per udara ini menggabungkan kemampuan per konvensional dari tingkat sangat keras, hingga sangat lembut dalam satu paket [3].

\section{Komponen dan Cara Kerja Air Suspension}

Air suspension digunakan sebagai pengganti fungsi pegas. Saat ini air suspension banyak diaplikasikan pada berbagai mobil, bus dan trailer. Dalam sistem ini tekanan udara dapat diatur sesuai beban kendaraan. Kompresor akan menyuplai udara bertekanan tersebut ke tabung penyimpanan udara bertekanan. Saat mesin hidup, tenaga mesin akan menggerakan kompresor tersebut, kemudian udara dimasukkan kedalam kantong udara yang berada pada kaki-kaki melalui katup selenoid. Kantong udara layaknya sebuah shock absorber yang dapat bergerak naik turun namun didesain lebih rapat karena berisi udara bertekanan. Karena udara bersifat dapat dikompresi, menyebabkan volume kantong udara akan berubahubah saat mendapat beban yang bervariasi, udara dalam kantong udara akan mengembang dan mengempis sesuai beban yang diterima. Hal itulah yang menyebabkan air suspension dapat menyerap getaran [4].

Hal lain yang unik pada sistem ini adalah ground clearence dapat di stel sesuai keinginan dan keadaan, pada sistem ini terdapat tombol dan indikator untuk mengatur jumlah udara yang 
dikompresikan ke kantong udara. Sehingga ketinggian kantong udara dapat disesuaikan yang akan mempengaruhi ground clearence.

\section{Komponen Utama}

1. Kompresor udara

Kompresor berfungsi untuk memompa dan menciptakan tekanan pada udara. Mengingat sistem ini memanfaatkan tekanan udara sebagai peredam.

\section{Tabung penyimpanan}

Tabung ini fungsinya sebagai penyimpan cadangan udara ketika sistem bekerja. Hal ini akan mencegah kekurangan udara saat sistem bekerja.

3. Selang udara bertekanan tinggi

Selang ini akan menghubungkan tiap komponen yang harus dialiri udara bertekanan tinggi. Oleh sebab itu, selang udara haruslah kuat.

4. Kantong udara

Kantong udara adalah tempat udara tersebut menerima beban kendaraan. Volume kantong udara akan berubah-ubah sesuai beban kendaraan.

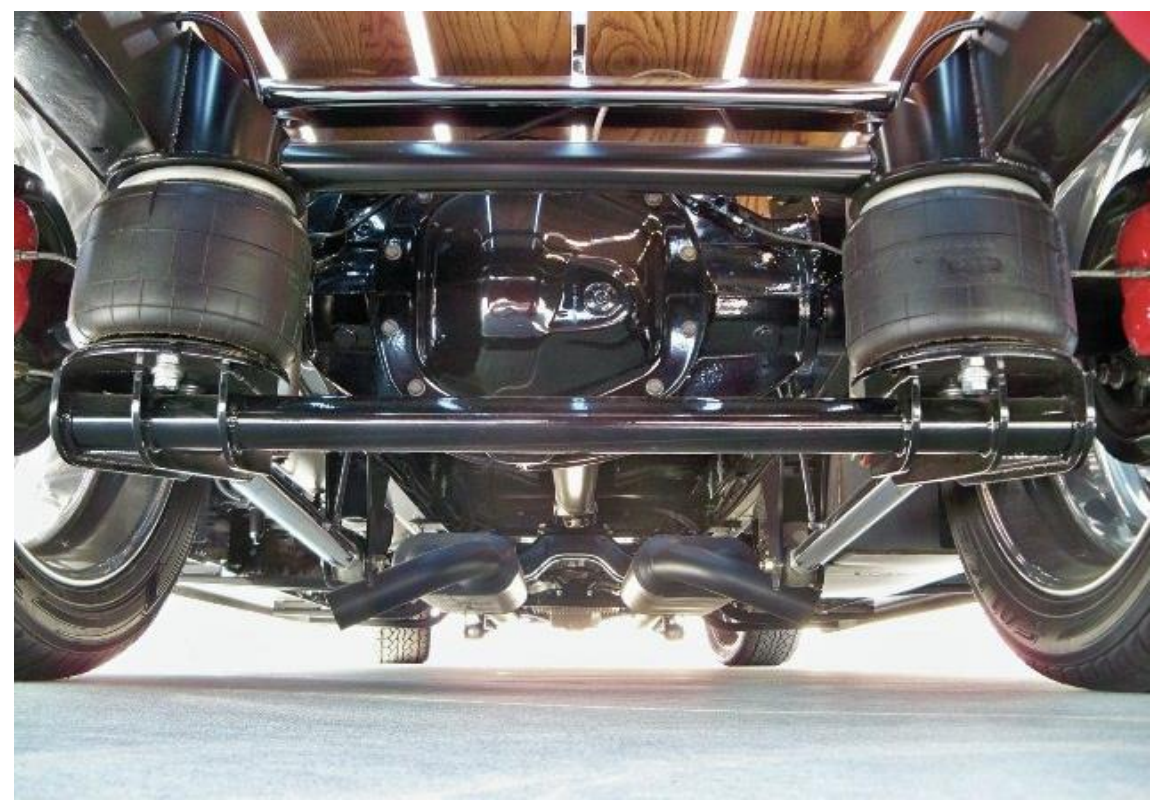

Gambar 1. Air Suspension [3]. 


\section{Jenis Air Suspension}

1. Tipe strut/silinder

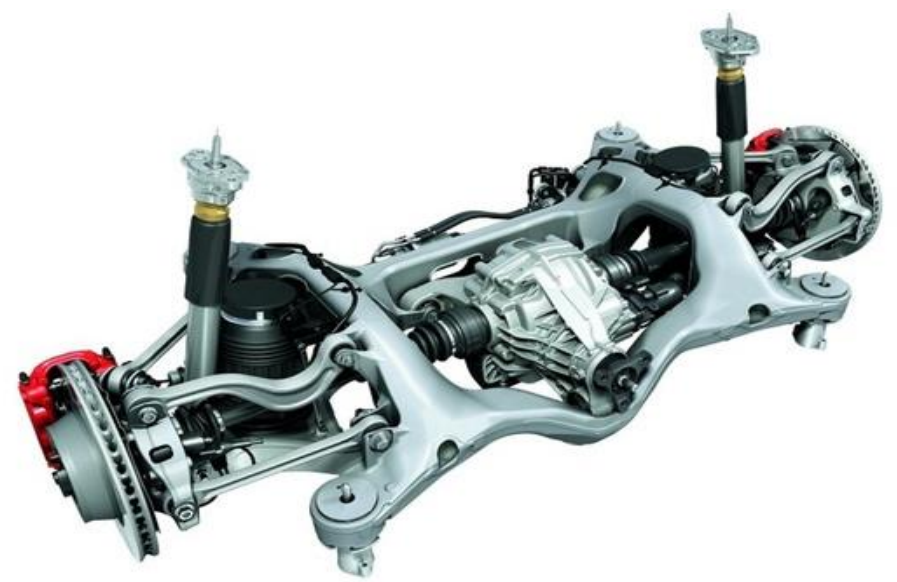

Gambar 2.strut/silinder [4].

Pada tipe silinder, pegas dan shock absorber dijadikan satu. Tipe ini tidak memakan banyak tempat namun tipe ini memiliki bantingan lebih keras, cocok untuk mobil-mobil ringan yang memiliki ruang sempit, tipe ini juga cocok untuk sport car dengan suspensi cenderung keras akan menstabilkan mobil pada kecepatan tinggi.

\section{Type Bag (Air Suspension Balon)}

Tipe ini disebut sebagai tipe balon karena kantong udara berbentuk layaknya balon. Pada tipe balon, rebound terhadap guncangan lebih lembut dan empuk sehingga terasa lebih nyaman. Namun, tipe ini membutuhkan ruang yang besar untuk penempatannya. Itulah sebabnya tipe balon banyak digunakan untuk kendaraan seperti truk dan bus yang memiliki kolong chasis yang luas [4].

\section{Kesimpulan}

Dengan suspensi udara, tidak akan muncul suara gesekan besi yang mungkin akan membuat telinga bising di dalam kendaraan, berbeda dengan suspensi baja yang pastinya ketika terjadi goncangan, naik turun dari pegas baja akan bergesek dengan partikel lain yang memunculkan suara suara bising di telinga. Suspensi udara memang terlihat cara kerjanya cukup sederhana, akan tetapi, dengan menggunakan teknologi suspensi udara ini, perawatan kendaraan terutama pada suspensi jelas memerlukan perawatan yang lebih rumit, dan biaya yang mahal [5]. 


\section{Referensi}

[1] F. Hanif, S. Munahar, and D. S. Putra, "Pengembangan Sirkuit Security System u ntuk Meningkatkan Driver Behaviour Control pada Kendaraan," Automotive Experiences, vol. 1, no. 1, pp. 13-19, 2018.

[2] Bluestar, "Your Vehicle's Suspension System," bluestar.com, 2018.

[3] N. Team, "Sejarah Air Suspension," National Modificator \& Aftermarket Association, 2017.

[4] Amrie Muchta, "Fungsi dan Cara Kerja Air Suspension (suspensi udara) Pada Bus," AutoExpose, 2015.

[5] Michael Elkan, "Kelebihan Dan Kelemahan Air Suspension,” Tentang Air Suspensi, 2017. 